\title{
A case of elongated cervical canal
}

L D R Tsatsi
MB ChB, FCRad(D)SA
S Ahmad
MB BS
Department of Diagnostic Radiology
Medical University of Southern Africa

A 29-year-old black female patient presented to the gynaecology department at Ga-Rankuwa Hospital in February 2002 with a complaint of primary infertility.

\section{Findings}

All haematological and clinical parameters were normal.

\section{Ultrasound}

Ultrasound examination revealed a large uterus with multiple intramural, submucosal and subserosal fibroids. Two huge fibroids were noted. The dimensions were $10.3 \mathrm{~cm}$ x $8.9 \mathrm{~cm}$ and $8.9 \mathrm{~cm} \mathrm{x} 5.7 \mathrm{~cm}$. No localised area of cystic breakdown was noted (Figs 1 and 2).

\section{CT}

An axial CT scan was performed in June 2002. The findings were as follows: A large myometous uterus was visible. Multiple subserosal intramural and submucosal fibroids were noted. The dimensions of the two largest fibroids were $10.1 \times 9.4 \mathrm{~cm}$ and $6.9 \times 7.1 \mathrm{~cm}$.

Density measurements were of soft tissue, i.e. 30 - 40 HFU. No calcifi-

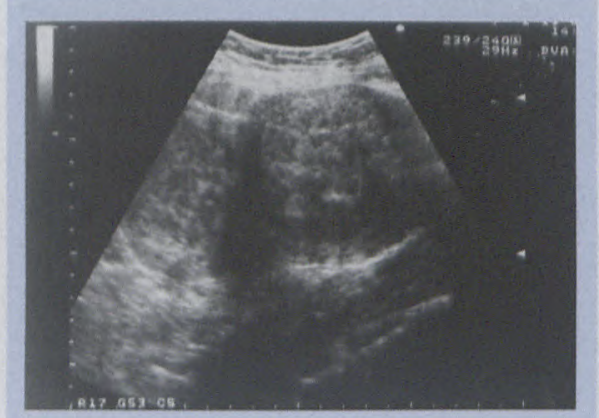

Fig. 1. Transverse sonar scans showing two huge fibroids.

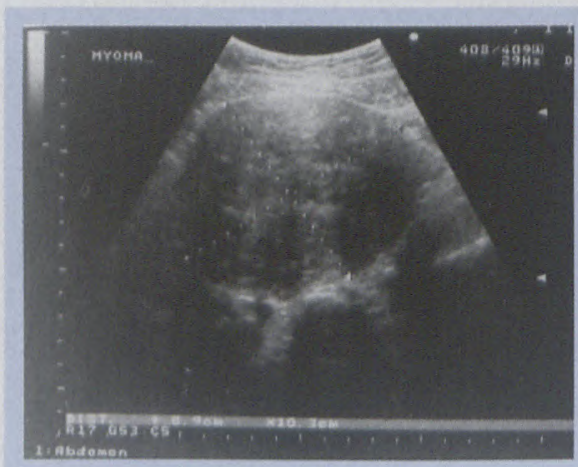

Fig. 2. Transverse sonar scans of the largest fibroid.

cation or areas of breakdown were noted. Coronal and sagittal reconstructions were also performed (Figs 3 and 4).

\section{Hysterosal pingography (HSG)}

This demonstrated an extremely elongated cervical canal $(15 \mathrm{~cm})$. A filling defect was demonstrated at the fundus of the uterus. The filling defect (fibroid) was demonstrated in all views of hysterosal pingography. The uterus was noted to extend to the extent of $\mathrm{L} / 4$ vertebra.

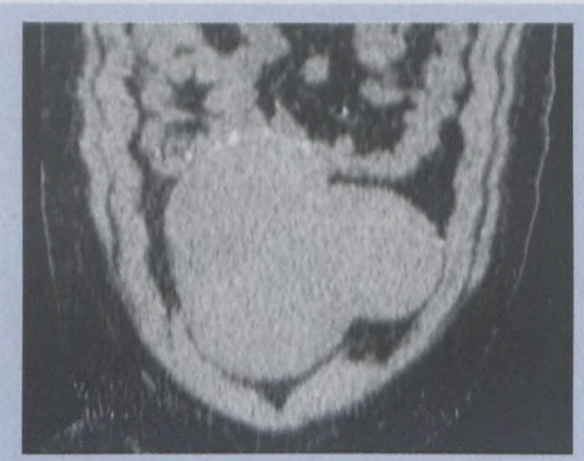

Fig. 3. Post HSG - Reconstructed coronal CT showing fibroid uterus with contrast in the peritoneal cavity.

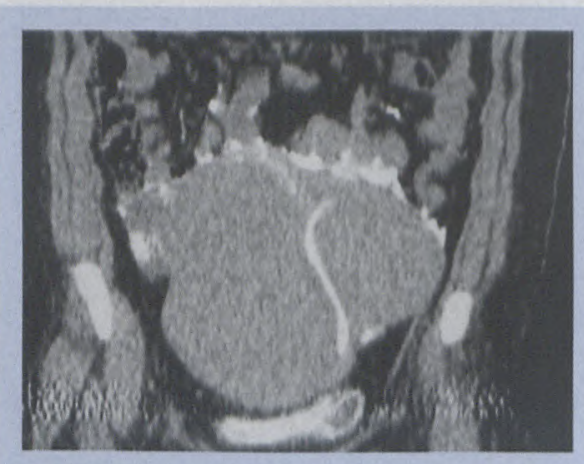

Fig. 4. Coronal reconstructed CT images showing a long cervical canal interspersed between two huge fibroids.

Opacification of the left tubule system was demonstrated and an accompanying free spill was noted. The right tube showed a tapering proximal filling with complete blockage (Figs 5 and 6).

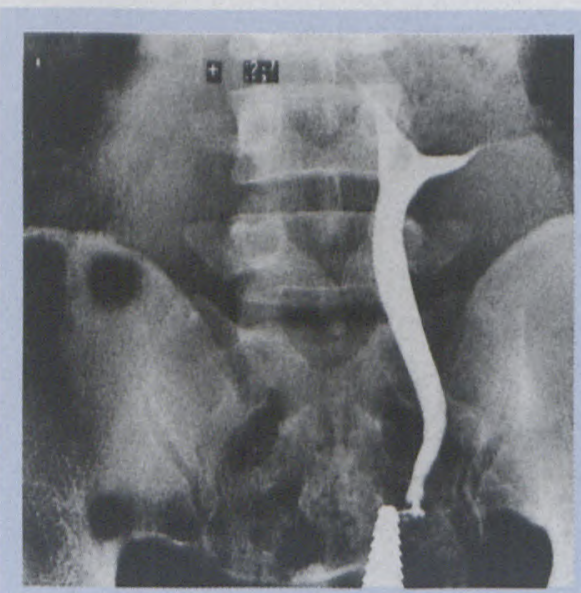

Fig. 5. A very long cenvical canal with the uterus becoming an abdominal organ. 


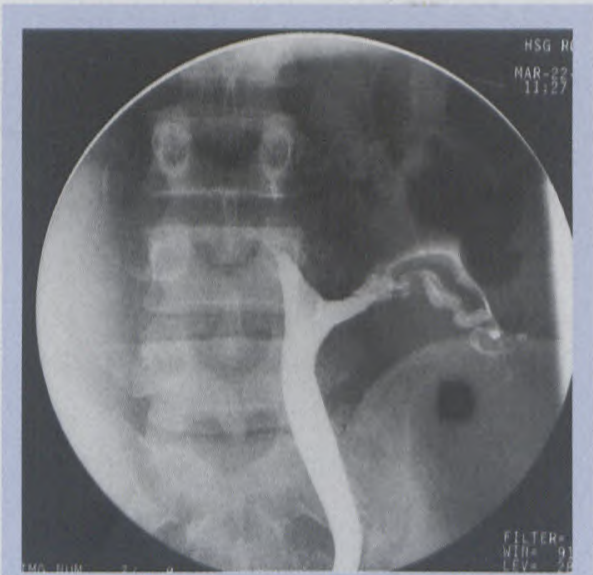

Fig. 6. HSG performed in March 2002 showing a long cervical canal. A small filling in the area of fundus of the uterus with opacification of the left fallopian tube only, showing peritoneal spill as well.

\section{Conclusion}

To the best of our knowledge similar elongation of the cervical canal has not been described previously.

The cervical canal, which is best shown on HSG with the vaccum injector, is usually $30-40 \mathrm{~mm}$ long and tends to become shorter after childbirth. ${ }^{1,2}$ The cervical canal is about one-third of the entire length of the uterus and is often spindleshaped. ${ }^{47}$

The cervical canal extends upward $1-2 \mathrm{~cm}$ from the external os to the internal os, above which there is a short narrow isthmus, which opens into the general uterine cavity. The width of the cervical canal varies with the menstrual cycle, being wider in the proliferation than in secretory phase 2 .

\section{References}

1. Whitehouse $\mathrm{GH}$, Wright $\mathrm{CH}$. Imaging in gynaecology. In: Grainger RG, Allison D. Diagnostic Radiology. 4th ed. London: Churchill Livingstone, 2001: 1827.

2. Highman JH, Lees WR. Gynaecological imaging. In: Sutton D. Textbook of Radiology and Imaging. 5th ed. London: Churchill Livingstone, 1993: 1212.

3. Slezak P, Tillinger KG. The occurrence and signficance of broad longitudinal folds in the uterine cavity at hysterography. Radiology 1973; 106: 87-90.

4. Slezak P, Tillinger KG. The incidence and clinical importance of hysterographic evidence of cavities in the uterine wall. Radiology; 1976: 581-586.

5. Slezak P, Tillinger KG. The significance of the spiculated outline of the uterine cavity on hysterography. Radiology 1973; 107: 527-531.

6. Slezak P, Tillinger KG. The occurrence and significance of a double-outlined uterine cavity (DOUC) in the hysterographic picture. Radiology 1968; 90: 756-760.

7. Gerlock AJ, Hooser CW. Oviduct response to glucagon during hysterosalpingography. Radiology 1976; 119: 727-728.

\section{Imaging of Diseases of the Chest $3 / e$}

Peter Armstrong, Alan G Wilson, P Dee \& D M Hansell This comprehensive resource covers all imaging aspects of the lungs, the pleura and the mediastinum and integrates all available imaging modalities. Both common and uncommon disorders are included, whilst the logical, clinical organisation of the text allows for fast, efficient access to the information you require.

\section{Features}

- Includes all you need to know in one convenient singlevolume resource.

- Multi-modality coverage ensures that all the modalities applicable to thoracic imaging are included.

- Includes nearly 2000 high-quality images and illustrations, covering a wide variety of cases.

- Chapters are organised by diseases and disorders, allowing for fast navigation through the text.

- Chapter outlines, Summary tables and Key points boxes summarise the most important information.

2000, hardback, 1056 pp, 1800 illus., Mosby, R2 990

\section{Special offer: Buy Imaging of Diseases of the Chest $3 / e$ and receive a free Kumar and Clarke Clinical Medicine 4/e}

ORDERS: South African Medical Association, Private Bag X1, Pinelands 7430. Tel (021) 530-6527 Fax (021) 531-4126 E-mail: fpalm @samedical.org Limited local stock.

\section{THE 23rd COURSE IN COMPUTED TOMOGRAPHY AND MAGNETIC RESONANCE IMAGING 13 - 17 APRIL 2003}

at the Gleneagles Hotel, Auchterarder, Scotland Organisers: Professor Janet E Husband OBE FMedSci FRCP FRCR \& Mrs Tiba Seear DCRR

We are pleased to announce the 23rd Course in Whole Body Computed Tomography and Magnetic Resonance Imaging. The Course is recognised by The Royal College of Radiologists for the Continuing Professional Development Accreditation of 26 RCR CPD Credits and by the European Accreditation Council for 26 European CME Credits.

The course emphasises state of the art body CT and MR imaging.

The course is designed for radiologists and may also interest radiographers. The programme consists of formal lectures along with a choice of special workshops. There will also be a technical exhibition and bookshop.

For registration forms and further details, please contact: London CT Course Ltd, Secretariat Office, 36 Portland Place, London, W1B 1AT, UK. Tel: +44 (0) 207307 1411, Fax: +44 (0) 2073071414 ,

E-mail: enquiries@ctmricourse.co.uk or visit our website http://www.ctmricourse.co.uk 